\section{D) Check for updates}

Cite this: Org. Chem. Front., 2021, 8 . 6026

Received 29th July 2021,

Accepted 22nd August 2021

DOI: $10.1039 / \mathrm{d} 1 \mathrm{qo} 01104 a$

rsc.li/frontiers-organic

\title{
Deoxygenative nucleophilic difluoromethylselenylation of carboxylic acids and alcohols with $\mathrm{BT}-\mathrm{SeCF}_{2} \mathrm{H} \dagger$
}

\author{
Matteo Tironi, Stefan Dix and Matthew N. Hopkinson (iD *
}

The benzothiazolium salt $\mathrm{BT}-\mathrm{SeCF}_{2} \mathrm{H}$ is introduced as an efficient nucleophilic reagent for transferring difluoromethylselenyl groups onto organic molecules. SeCF $2 \mathrm{H}$-Containing selenoesters could be prepared upon deoxygenative substitution of readily available carboxylic acids, while silver catalysis allowed for efficient formation of (difluoromethyl)selenoethers, including the established electrophilic reagent $\mathrm{BnSeCF}_{2} \mathrm{H}$, directly from simple alcohols. To the best of our knowledge, these deoxygenative reactions represent the first reported nucleophilic difluoromethylselenylation processes and thus open up new approaches to prepare valuable fluorinated compounds.

\section{Introduction}

Incorporating fluorine atoms and larger fluorine-containing functional groups is a tried and tested method for modulating the physical characteristics, biological activity and bioavailability of organic compounds. ${ }^{1}$ While well-established moieties such as the $\mathrm{CF}_{3}$ group remain the most widely studied, the investigation of alternative fluorinated motifs that offer new possibilities for fine-tuning a molecule's properties has become a major area of research. ${ }^{2}$ Organoselenium derivatives are fundamental for many biological functions, with selenium itself being an essential human micronutrient. Multiple selenoethers and selenoesters have accordingly attracted attention as potential therapeutics including as anticancer, anti-microbial and anti-viral agents. ${ }^{3}$ Selenium derivatives have also found applications in materials science ${ }^{4}$ and as versatile synthetic intermediates and catalysts, especially in oxidation and radical chemistry. ${ }^{5}$

Combining the beneficial effects of fluorine substitution with organoselenium chemistry is an attractive approach for developing new functional (bio)molecules and materials. In recent years, significant research interest has focused on fluoroalkylselenyl groups with the $\mathrm{SeCF}_{3}$ moiety in particular being the subject of several studies. ${ }^{6}$ The difluoromethylselenyl group $\left(\mathrm{SeCF}_{2} \mathrm{H}\right)$, on the other hand, has been less extensively investigated despite the well-known advantages partially fluori-

Institut für Chemie und Biochemie, Freie Universität Berlin, Fabeckstrasse 34-36, 14195 Berlin, Germany. E-mail: matthew.hopkinson@fu-berlin.de

$\dagger$ Electronic supplementary information (ESI) available: Experimental procedures, reaction optimisation, and characterisation data. See DOI: 10.1039/ d1qo01104a nated groups can offer over the corresponding perfluoro analogues (e.g. lipophilicity modulation, conformational effects, potential for hydrogen bonding). ${ }^{1,7}$ One reason for the lack of studies on the $\mathrm{SeCF}_{2} \mathrm{H}$ group is the scarcity of synthetic routes to access it. Traditionally, indirect methods involving either insertion of difluorocarbene into a selenol ${ }^{8}$ or formal nucleophilic difluoromethylation of a diselenide or cyanoselenide were employed. ${ }^{9}$ Direct difluoromethylselenylation methods, in which $\mathrm{SeCF}_{2} \mathrm{H}$ is installed as a whole group, do not require access to a selenium-containing precursor and allow $\mathrm{SeCF}_{2} \mathrm{H}$ to be more readily studied alongside other fluorinated or nonfluorinated groups in structure-activity relationship (SAR) investigations. To date, however, only two reagent classes have been developed for direct difluoromethylselenylation, with both serving as electrophilic or radical sources of the $\mathrm{SeCF}_{2} \mathrm{H}$ group. The selenoether $\mathrm{BnSeCF}_{2} \mathrm{H}(\mathbf{A}$, Scheme 1a), which is itself produced only in low yield (13-36\%) from BnSeCN, typically requires in situ activation with $\mathrm{SO}_{2} \mathrm{Cl}_{2}$, with $\mathrm{ClSeCF}_{2} \mathrm{H}$ serving as the actual difluoromethylselenylation reagent. ${ }^{10}$ Sulfonyl derivatives $\mathbf{B}(\mathrm{Ar}=\mathrm{Ph}, p$-Tol, Scheme 1a) react under milder conditions but are themselves synthesised from A. ${ }^{11}$ While nucleophilic approaches are commonly employed to install the $\mathrm{SeCF}_{3}$ group, to the best of our knowledge, no direct nucleophilic difluoromethylselenylation method has been reported and there are currently no sources of the ${ }^{-} \mathrm{SeCF}_{2} \mathrm{H}$ anion available.

In 2019, we introduced 2-fluoroalkylchalcogenyl-substituted benzothiazolium salts as new reagents for installing fluorinecontaining groups onto organic molecules. These BT-reagents can be prepared from relatively inexpensive starting materials and serve as practical sources of fluoroalkylchalcogenyl anions in synthetically appealing deoxygenative functionalisation reac- 
a) Reported Difluoromethylselenylation Reagents: All Electrophilic/Radical

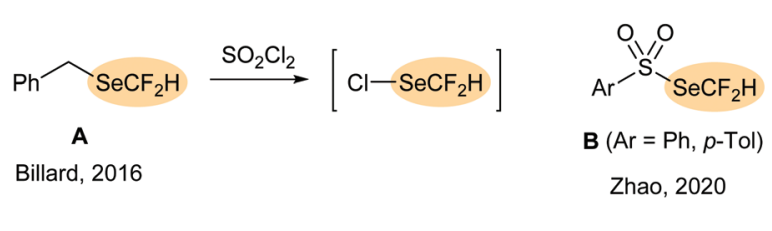

b) This Work: Nucleophilic Difluoromethylselenylation using $\mathrm{BT}-\mathrm{SeCF}_{2} \mathrm{H}$

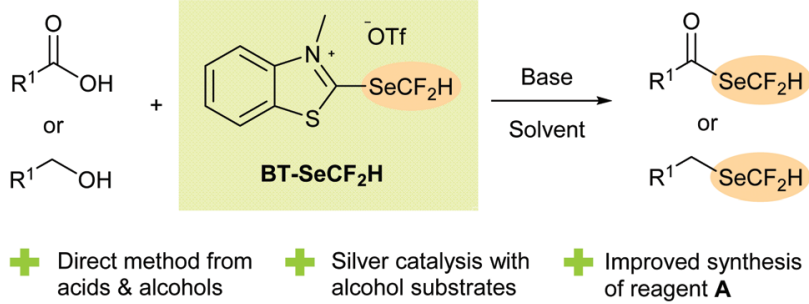

Scheme 1 (a) Established electrophilic and radical difluoromethylselenylation reagents. (b) This work: $\mathrm{BT}-\mathrm{SeCF}_{2} \mathrm{H}$ as a nucleophilic reagent in deoxygenative substitution reactions of carboxylic acids and aliphatic alcohols.

tions of readily available aliphatic alcohols ${ }^{12}$ and carboxylic acids. $^{13,14}$ In addition to perfluoroalkyl derivatives such as BT-SR ${ }_{\mathrm{F}}\left(\mathrm{R}_{\mathrm{F}}=\mathrm{C}_{n} \mathrm{~F}_{2 n-1}\right)$ and $\mathrm{BT}-\mathrm{SeCF}_{3}$, recent work showed that the partially fluorinated analogue BT- $\mathrm{SCF}_{2} \mathrm{H}$ could be successfully engaged in efficient deoxygenative difluoromethylthiolation reactions, providing (difluoromethyl)thioesters directly from carboxylic acids under mild conditions. ${ }^{13}$ Inspired by these results, we considered whether a (difluoromethyl)selenium analogue could be accessed and, if so, whether it would act as a source of hitherto unexplored ${ }^{-} \mathrm{SeCF}_{2} \mathrm{H}$ anions for nucleophilic transformations. Herein, we report the successful synthesis of $\mathrm{BT}-\mathrm{SeCF}_{2} \mathrm{H}$ and its application as a reagent in unprecedented deoxygenative difluoromethylselenylation reactions (Scheme 1b). In addition to providing $\mathrm{SeCF}_{2} \mathrm{H}$-containing selenoesters from diverse carboxylic acids, silver catalysis allowed for the efficient synthesis of (difluoromethyl)selenoethers, including the established electrophilic reagent $\mathrm{BnSeCF}_{2} \mathrm{H}$ (A), directly from unactivated alcohols.

\section{Results and discussion}

\section{Synthesis of BT-SeCF ${ }_{2} \mathrm{H}$}

The synthesis of the new benzothiazolium salt $\mathrm{BT}-\mathrm{SeCF}_{2} \mathrm{H}$ is shown in Scheme 2. As for the other BT-reagents, ${ }^{12-14}$ a twostage approach was envisaged proceeding through a neutral non-methylated benzothiazole intermediate. In the first step, bis(benzothiazole)diselenide $\mathbf{1}^{15}$ was reduced to the corresponding selenol using $\mathrm{NaBH}_{4}$. Following precipitation as the benzothiazolium chloride adduct, subsequent treatment with difluorocarbene generated under basic conditions from $\mathrm{HCF}_{2} \mathrm{OTf}$ afforded the stable heteroarene 2, which could be isolated in $71 \%$ yield upon column chromatography.

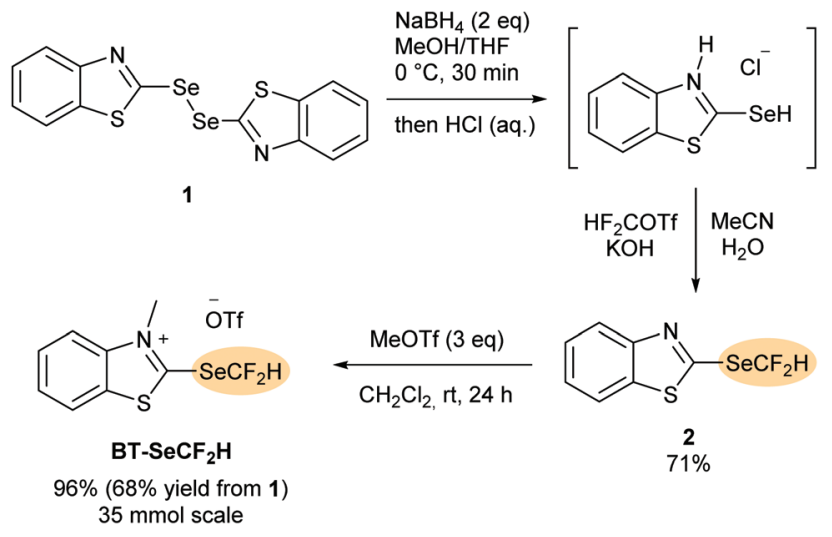

Scheme 2 Synthesis of BT-SeCF $2 \mathrm{H}$.

$\mathrm{N}$-Methylation using methyl trifluoromethanesulfonate in $\mathrm{CH}_{2} \mathrm{Cl}_{2}$ at $\mathrm{rt}$ followed by precipitation with diethyl ether afforded BT-SeCF ${ }_{2} \mathrm{H}$ in $96 \%$ yield (overall yield of $68 \%$ from 1 , $35 \mathrm{mmol}$ scale). BT-SeCF${ }_{2} \mathrm{H}$ was obtained as an off-white solid that required no further purification and is stable at least over several months when stored under air at room temperature.

\section{Deoxydifluoromethylselenylation of carboxylic acids}

With $\mathrm{BT}-\mathrm{SeCF}_{2} \mathrm{H}$ in hand, we sought to investigate its reactivity as a nucleophilic difluoromethylselenylating reagent. Inspired by the successful application of $\mathrm{BT}-\mathrm{SCF}_{2} \mathrm{H}$ in deoxygenative substitution reactions of carboxylic acids, ${ }^{13} \mathrm{BT}^{-\mathrm{SeCF}_{2} \mathrm{H}}(1.25$ eq.) was first reacted with $n$-dodecanoic acid $3 \mathbf{a}$ and $\mathrm{NaH}(2$ eq.) in THF. After $2 \mathrm{~h}$ at rt, we were delighted to observe clean formation of the (difluoromethyl)selenoester $4 \mathrm{a}$ in $45 \% \mathrm{NMR}$ yield. Selenoesters have found multiple applications as pharmaceutical candidates and synthetic reagents, but studies on difluoromethyl derivatives are lacking. ${ }^{16}$ In 2020, Wang and co-workers reported the only methodology for preparing (difluoromethyl)selenoesters; a radical process from aldehydes employing $\mathrm{BnSeCF}_{2} \mathrm{H}(\mathbf{A})$ together with AIBN. ${ }^{10 f}$ The successful synthesis of (difluoromethyl)selenoesters using $\mathrm{BT}-\mathrm{SeCF}_{2} \mathrm{H}$ not only offers a complementary route starting from readily available carboxylic acids, it also represents the first reported nucleophilic difluoromethylselenylation process. Mechanistically, 4a likely results from an initial attack of the carboxylate to the 2-position of $\mathrm{BT}-\mathrm{SeCF}_{2} \mathrm{H}$ followed either by elimination of ${ }^{-} \mathrm{SeCF}_{2} \mathrm{H}$ and subsequent addition/elimination to a 2-carboxybenzothiazolium intermediate, or alternatively through a concerted rearrangement process.t Increasing the amount of $\mathrm{BT}-\mathrm{SeCF}_{2} \mathrm{H}$ to 2 eq. and raising the reaction temperature to $45{ }^{\circ} \mathrm{C}$ improved the NMR yield to $81 \%$, with 4 a being isolated in $78 \%$ yield after column chromatography.

The scope of the deoxygenative difluoromethylselenylation reaction was then tested with a range of carboxylic acid derivatives 3 (Scheme 3). A wide selection of aliphatic substrates

† A concerted mechanism proceeding through a 4-membered transition state was suggested by DFT studies on the related deoxydifluoromethylthiolation of carboxylic acids with BT-SCF ${ }_{2} \mathrm{H}$ (see ref. 13). 


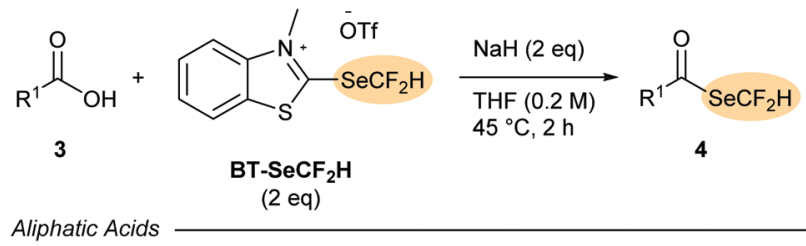

$$
{ }_{T_{n}}^{O}{ }_{\mathrm{SeCF}_{2} \mathrm{H}}
$$<smiles>O=C([Se]C(F)(F)F)C(c1ccccc1)c1ccccc1</smiles>

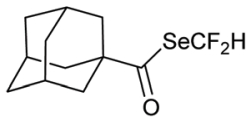

4a $(\mathrm{n}=10) \quad 78 \%$ $4 b(n=12) \quad 87 \%$ 4c $(n=16) \quad 86 \%$

4d $67 \%$

4e $89 \%$

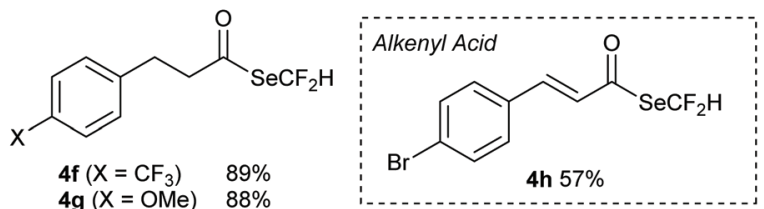

Aromatic Acids ${ }^{a}$<smiles>[X]c1ccc(C(=O)Sc2ccccc2)cc1</smiles>

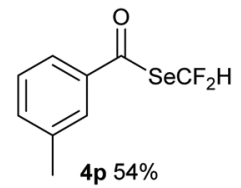<smiles>CCCC(=O)OC(=O)c1ccccc1C</smiles>

$4 \mathbf{i}(\mathrm{X}=\mathrm{Cl}) \quad 66 \%$

4j $(X=B r)$

$4 \mathbf{k}(X=1)$

4l $(X=\mathrm{OMe})$

$4 \mathrm{~m}\left(\mathrm{X}=\mathrm{NO}_{2}\right)$

4n $(X=P h)$

4o $(X=M e)$

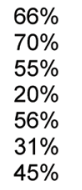

$\underbrace{}_{4 \mathbf{r} 53 \%}$

Pharmaceutical \& Natural Product Analogues<smiles>CCCCCCCCCCCCCC(=O)C(C)c1ccc(CC(C)C)cc1</smiles><smiles>CCOC(=O)C(C)C(=O)C(C)c1cccc(C(=O)c2ccccc2)c1</smiles>

4t (from Ibuprofen) $90 \%$

$4 u$ (from Ketoprofen)
$67 \%$<smiles>CC(C(=O)OC(F)(F)F)c1ccc2c(c1)CC(=O)c1ccccc1S2</smiles>

$4 \mathbf{v}$ (from Zaltoprofen) $80 \%$

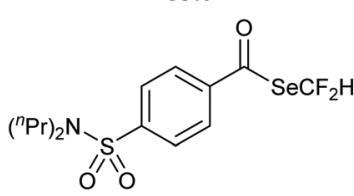

4x (from Probenecid) $65 \%$

Scheme 3 Scope of the deoxydifluoromethylselenylation of carboxylic acids. Conditions: 3 ( $0.3 \mathrm{mmol}$ ), BT-SeCF${ }_{2} \mathrm{H}$ (2 eq.), $\mathrm{NaH}$ (2 eq.) in THF $(0.2 \mathrm{M}), 45^{\circ} \mathrm{C}, 2 \mathrm{~h}$. Isolated yields. ${ }^{\mathrm{a}}$ Reactions conducted at $\mathrm{rt}$.

could be successfully converted into the corresponding (difluoromethyl)selenoesters $\mathbf{4 a}-\mathbf{g}$ in excellent yields (67-89\%). Primary, secondary and even tertiary derivatives were all tolerated with 1-adamantanecarboxylic acid $3 \mathrm{e}$ providing selenoester $4 \mathrm{e}$ in $89 \%$ yield after column chromatography. Aromatic acids could also be successfully employed with these reactions being conducted at room temperature. A wide range of functional groups were tolerated with electron-neutral and comparatively electron-deficient moieties leading to the highest yields. The successful formation of the halogen-substituted products $4 \mathbf{i}-\mathbf{k}$ is particularly noteworthy as these compounds could serve as $\mathrm{SeCF}_{2} \mathrm{H}$-containing building blocks amenable to subsequent functionalisation through cross-coupling. As demonstrated by the series $\mathbf{4 0 -}-\mathbf{q}$, substituents at the ortho-, meta- and para-positions were tolerated with little difference in the product yields observed.

Finally, the applicability of the deoxydifluoromethylselenylation method to the synthesis of $\mathrm{SeCF}_{2} \mathrm{H}$-containing pharmaceutical analogues was evaluated. A range of (difluoromethyl)selenoesters of common non-steroidal anti-inflammatory drugs (NSAIDs) could be prepared in excellent yields directly from the pharmaceutical compound (4t-w, 67-91\%). The sulphonamide probenecid $(\mathbf{3 x})$, which is used to treat gout, could also be converted in $65 \%$ yield, while the naturally occurring fatty acid linoleic acid (3y) provided selenoester $4 y$ in $92 \%$ yield.

\section{Deoxydifluoromethylselenylation of alcohols}

Having established the reactivity of $\mathrm{BT}-\mathrm{SeCF}_{2} \mathrm{H}$ as a nucleophilic reagent for the difluoromethylselenylation of carboxylic acids, we next turned our attention to the synthesis of selenoethers directly from aliphatic alcohols. Although more widely studied than (difluoromethyl)selenoesters, synthetic routes to alkyl-SeCF${ }_{2} \mathrm{H}$ compounds are largely limited to indirect methods that require pre-installation of a diselenide or cyanoselenide motif onto the substrate. ${ }^{9}$ To date, only a handful of direct difluoromethylselenylation reactions affording aliphatic products have been disclosed involving either nucleophilic attack onto in situ-activated $\mathrm{BnSeCF}_{2} \mathrm{H}(\mathbf{A})^{10 c, e}$ or, in a very recent report from Zhang and co-workers, radical group transfer from $\mathrm{PhSO}_{2} \mathrm{SeCF}_{2} \mathrm{H}(\mathbf{B}) .{ }^{11 c}$

In an initial test reaction, 4-nitrobenzyl alcohol 5a was reacted with $\mathrm{BT}-\mathrm{SeCF}_{2} \mathrm{H}$ (1.25 eq.) and $\operatorname{NEt}\left({ }^{\mathrm{i}} \mathrm{Pr}\right)_{2}$ (2 eq.) in MeCN at rt. After $2 \mathrm{~h},{ }^{1} \mathrm{H}$ and ${ }^{19} \mathrm{~F}$ NMR indicated the formation of the desired selenoether $\mathbf{6 a}$ in $42 \%$ yield. Increasing the amount of reagent and base and adding them in portions, as well as the optimisation of the temperature $\left(-40^{\circ} \mathrm{C}\right)$ and reaction time $(4 \mathrm{~h})$ allowed for an increase in the NMR yield of $\mathbf{6 a}$ to $65 \%$ with the pure product being isolated in $62 \%$ yield after column chromatography. At this stage, the generality of the method was tested with a selection of benzylic alcohols (Scheme 4). While a series of substrates bearing electron-withdrawing substituents such as $-\mathrm{CN},-\mathrm{CF}_{3}$ and $-\mathrm{CO}_{2} \mathrm{Me}$ provided the corresponding (difluoromethyl)selenoethers 6a-e in good yields, more electron-rich derivatives reacted only with low efficiency. Addition of these alcohols to the BT-reagent followed by elimination of ${ }^{-} \mathrm{SeCF}_{2} \mathrm{H}$ would lead to a comparatively less electrophilic 2-alkoxybenzothiazolium intermediate. Nucleophilic substitution at this species is likely less favoured, and decomposition of the ${ }^{-} \mathrm{SeCF}_{2} \mathrm{H}$ anion may outcompete product formation. With the aim of providing a stabilising 

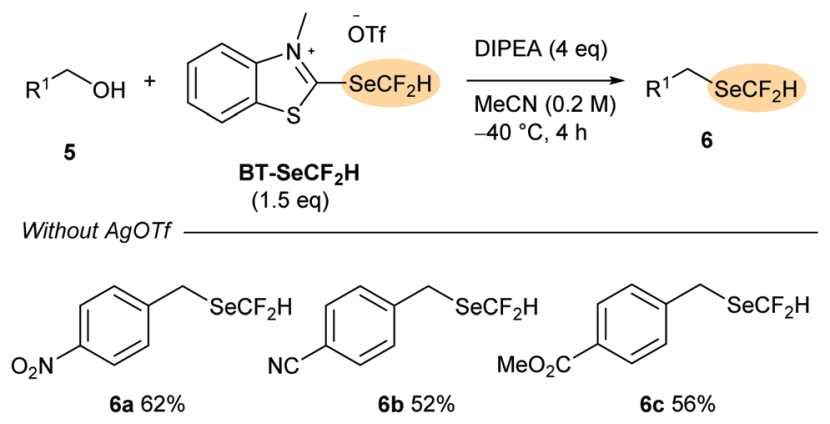

counter-cation, which could increase the lifetime of ${ }^{-} \mathrm{SeCF}_{2} \mathrm{H}$ in the reaction medium, silver(I) salts were tested as catalytic additives. While 4-bromobenzyl-containing selenoether $\mathbf{6 f}$ was provided in only $31 \%$ yield under the standard conditions described above, addition of $\mathrm{Ag}_{2} \mathrm{O}$ (0.25 eq., 0.5 eq. of $\left.\mathrm{Ag}^{+}\right)$led to an increase in NMR yield to $63 \%$. Moreover, selenoether $6 f$ was obtained in $81 \%$ NMR yield ( $67 \%$ isolated) when the reaction was conducted in the presence of AgOTf (0.5 eq.).

Under these silver catalysis conditions, good yields were obtained with a selection of electron-neutral and electron-rich benzyl alcohols $(\mathbf{5} \mathbf{g}-\mathbf{k}$, up to $95 \%$ with 4-(tert-butyl)benzyl alcohol $\mathbf{5 h}$ ), while the propargylic substrate $\mathbf{5 l}$ also reacted with moderate efficiency ( $42 \%$ yield of 61 ). Notably, the method is also tolerant of terminal alkynes $(\mathbf{6 k})$, which are known to be activated by silver(I). Finally, direct deoxytrifluoromethylselenylation of benzyl alcohol was tested as a method for preparing $\mathrm{BnSeCF}_{2} \mathrm{H}$ (A). This electrophilic and radical difluoromethylselenylation reagent was introduced by Billard and co-workers in $2016^{10 a}$ and has been previously synthesised from benzyl bromide in a two-step sequence involving nucleo- philic difluoromethylation of BnSeCN. ${ }^{10 a, e, 11 c}$ Subjecting $\mathrm{BnOH}$ to the optimised conditions with $\mathrm{BT}-\mathrm{SeCF}_{2} \mathrm{H}$ (1.5 eq.), AgOTf (0.5 eq.) and $\operatorname{NEt}\left({ }^{i} \mathrm{Pr}\right)_{2}$ (4 eq.) resulted in smooth formation of the established reagent $\mathbf{A}$, which could be isolated in $58 \%$ yield after column chromatography on a $2 \mathrm{mmol}$ scale. This yield is notably higher than that obtained in the previously-reported difluoromethylation of BnSeCN $(13-36 \%)^{10 a, e, 11 c}$ and suggests that direct deoxygenative difluoromethylselenylation could serve as a useful complementary approach to prepare reagent $\mathbf{A}$ and, by extension, its derivatives $\mathbf{B}$.

\section{Conclusions}

In conclusion, $\mathrm{BT}-\mathrm{SeCF}_{2} \mathrm{H}$ has been introduced as a practical reagent for hitherto unexplored nucleophilic difluoromethylselenylation reactions. Deoxygenative substitution of carboxylic acids provides (difluoromethyl)selenoesters, while silver catalysis allows for the efficient synthesis of benzylic and propargylic $\mathrm{CF}_{2} \mathrm{H}$-substituted selenoethers, including the established electrophilic reagent $\mathrm{BnSeCF}_{2} \mathrm{H}(\mathbf{A})$, directly from unactivated alcohols. In opening up nucleophilic approaches, we believe this work will inspire new routes towards difluoromethylselenylated compounds and accelerate the study of the $\mathrm{SeCF}_{2} \mathrm{H}$ group in medicinal and materials chemistry.

\section{Conflicts of interest}

M.N.H. and S.D. are co-inventors on a European and International Patent Application concerning the synthesis and use of benzothiazolium reagents for installing fluorine-containing functional groups (EP 3677576 A1; WO 2020141195 A1).

\section{Acknowledgements}

This work is funded by the Dahlem Research School, the Studienstiftung des deutschen Volkes (scholarship to M.T.) and the Deutsche Forschungsgemeinschaft (DFG, German Research Foundation) - Project-ID 387284271 - SFB 1349 (gefördert durch die Deutsche Forschungsgemeinschaft (DFG) - Projektnummer 387284271 - SFB 1349). Financial support from the Fonds der Chemischen Industrie (FCI, Sachkostenzuschuss) is also gratefully acknowledged. We would like to acknowledge the assistance of the Core Facility BioSupraMol supported by the DFG.

\section{Notes and references}

1 Selected reviews: (a) K. Müller, C. Faeh and F. Diederich, Fluorine in Pharmaceuticals: Looking Beyond Intuition, Science, 2007, 317, 1881; (b) S. Purser, P. R. Moore, S. Swallow and V. Gouverneur, Fluorine in medicinal chemistry, Chem. Soc. Rev., 2008, 37, 320; (c) R. Berger, 
G. Resnati, P. Metrangolo, E. Weber and J. Hulliger, Organic fluorine compounds: a great opportunity for enhanced materials properties, Chem. Soc. Rev., 2011, 40, 3496; (d) J. Wang, M. Sánchez-Roselló, J. L. Aceña, C. del Pozo, A. E. Sorochinsky, S. Fustero, V. A. Soloshonok and H. Liu, Fluorine in Pharmaceutical Industry: Fluorine-Containing Drugs Introduced to the Market in the Last Decade (2001-2011), Chem. Rev., 2014, 114, 2432; (e) T. Fujiwara and D. O'Hagan, Successful fluorine-containing herbicide agrochemicals, J. Fluorine Chem., 2014, 167, 16; (f) A. Harsanyi and G. Sandford, Organofluorine chemistry: applications, sources and sustainability, Green Chem., 2015, 17, 2081; (g) M. G. Campbell and T. Ritter, Modern Carbon-Fluorine Bond Forming Reactions for Aryl Fluoride Synthesis, Chem. Rev., 2015, 115, 612; (h) C. Ni and J. Hu, The unique fluorine effects in organic reactions: recent facts and insights into fluoroalkylations, Chem. Soc. Rev., 2016, 45, 5441; (i) R. Szpera, D. F. J. Moseley, L. B. Smith, A. J. Sterling and V. Gouverneur, The Fluorination of $\mathrm{C}-\mathrm{H}$ Bonds: Developments and Perspectives, Angew. Chem., Int. Ed., 2019, 58, 14824; (j) T. Koike and M. Akita, Recent progress in photochemical radical di- and mono-fluoromethylation, Org. Biomol. Chem., 2019, 17, 5413; (k) M. Inoue, Y. Sumii and N. Shibata, Contribution of Organofluorine Compounds to Pharmaceuticals, ACS Omega, 2020, 5, 10633.

2 D. Cahard and J.-A. Ma, Emerging Fluorinated Motifs: Synthesis, Properties and Applications, Wiley-VCH, Weinheim, 2020.

3 Selected reviews: (a) C. W. Nogueira, G. Zeni and J. B. T. Rocha, Organoselenium and Organotellurium Compounds: Toxicology and Pharmacology, Chem. Rev., 2004, 104, 6255; (b) M. P. Rayman, Selenium and human health, Lancet, 2012, 379, 1256; (c) V. K. Jain and K. I. Priyadarsini, Organoselenium Compounds in Biology and Medicine: Synthesis, Biological and Therapeutic Treatments, Royal Society of Chemistry, Cambridge (UK), 2018.

4 Selected reviews: (a) M. A. Malik, M. Afzaal and P. O'Brien, Precursor Chemistry for Main Group Elements in Semiconducting Materials, Chem. Rev., 2010, 110, 4417; (b) Q. Li, Y. Zhang, Z. Chen, X. Pan, Z. Zhang, J. Zhu and $\mathrm{X}$. Zhu, Organoselenium chemistry-based polymer synthesis, Org. Chem. Front., 2020, 7, 2815.

5 Selected reviews: (a) A. T. Diplock and F. D. Kurzer, Organic Selenium Compounds: Their Chemistry and Biology, Biochem. Soc. Trans., 1974, 2, 571; (b) T. Wirth, Organoselenium Chemistry in Stereoselective Reactions, Angew. Chem., Int. Ed., 2000, 39, 3740; (c) D. M. Freudendahl, S. A. Shahzad and T. Wirth, Recent Advances in Organoselenium Chemistry, Eur. J. Org. Chem., 2009, 1649; (d) D. Freudendahl, S. Santoro, S. Shahzad, C. Santi and T. Wirth, Green Chemistry with Selenium Reagents: Development of Efficient Catalytic Reactions, Angew. Chem., Int. Ed., 2009, 48, 8409.

6 Reviews: (a) A. Tlili, E. Ismalaj, Q. Glenadel, C. Ghiazza and T. Billard, Synthetic Approaches to Trifluoromethylselenolated
Compounds, Chem. - Eur. J., 2018, 24, 3659; (b) C. Ghiazza and A. Tlili, Copper-promoted/copper-catalyzed trifluoromethylselenolation reactions, Beilstein J. Org. Chem., 2020, 16,305 .

7 (a) J. A. Erickson and J. I. McLoughlin, Hydrogen Bond Donor Properties of the Difluoromethyl Group, J. Org. Chem., 1995, 60, 1626; (b) Q. A. Huchet, B. Kuhn, B. Wagner, H. Fischer, M. Kansy, D. Zimmerli, E. M. Carreira and K. Müller, On the polarity of partially fluorinated methyl groups, J. Fluorine Chem., 2013, 152, 119; (c) Y. Zafrani, D. Yeffet, G. Sod-Moriah, A. Berliner, D. Amir, D. Marciano, E. Gershonov and S. Saphier, Difluoromethyl Bioisostere: Examining the "Lipophilic Hydrogen Bond Donor" Concept, J. Med. Chem., 2017, 60, 797.

8 (a) H. Suzuki, M. Yoshinaga, K. Takaoka and Y. Hiroi, Simple Synthesis of Aryl Difluoromethyl Selenides and Tellurides, Synthesis, 1985, 497; (b) V. P. Mehta and M. F. Greaney, S-, N-, and, Se-Difluoromethylation Using Sodium Chlorodifluoroacetate, Org. Lett., 2013, 15, 5036; (c) N. B. Heine and A. Studer, Radical Difluoromethylation of Thiols with (Difluoromethyl)triphenylphosphonium Bromide, Org. Lett., 2017, 19, 4150.

9 (a) Y.-m. Lin, W.-b. Yi, W.-z. Shen and G.-p. Lu, A Route to $\alpha$-Fluoroalkyl Sulfides from $\alpha$-Fluorodiaroylmethanes, $\mathrm{Org}$. Lett., 2016, 18, 592; (b) T. Dong, J. Nie and C.-P. Zhang, A convenient, transition metal-free synthesis of difluoromethyl selenoethers from organic selenocyanates and $\mathrm{TMSCF}_{2} \mathrm{H}$, Tetrahedron, 2018, 74, 5642; (c) S. Jin, Z. Kuang and Q. Song, Precise Construction of $\mathrm{SCF}_{2} \mathrm{H}$ or $\mathrm{SeCF}_{2} \mathrm{H}$ Groups on Heteroarenes Generated in Situ from $\mathrm{CF}_{3^{-}}$ Containing 1,3-Enynes, Org. Lett., 2020, 22, 615.

10 (a) Q. Glenadel, E. Ismalaj and T. Billard, Benzyltrifluoromethyl (or Fluoroalkyl) Selenide: Reagent for Electrophilic Trifluoromethyl (or Fluoroalkyl) Selenolation, J. Org. Chem., 2016, 81, 8268; (b) C. Ghiazza, T. Billard and A. Tlili, Trifluoromethyl- and Fluoroalkylselenolations of Alkynyl Copper(I) Compounds, Chem. - Eur. J., 2017, 23, 10013; (c) C. Ghiazza, Q. Glenadel, A. Tlili and T. Billard, Trifluoromethylselenolation and Fluoroalkylselenolation of Alkenes by Electrophilic Addition, Eur. J. Org. Chem., 2017, 3812; (d) Q. Glenadel, E. Ismalaj and T. Billard, A Metal-Free Route to Heterocyclic Trifluoromethyl- and Fluoroalkylselenolated Molecules, Org. Lett., 2018, 20, 56; (e) C. Ghiazza, A. Tlili and T. Billard, Direct $\alpha-\mathrm{C}-\mathrm{H}$ Trifluoromethylselenolation of Carbonyl Compounds, Eur. J. Org. Chem., 2018, 3680; (f) R.-L. Guo, X.-Q. Zhu, X.-L. Zhang and Y.-Q. Wang, Synthesis of difluoromethylselenoesters from aldehydes via a radical process, Chem. Commun., 2020, 56, 8976.

11 (a) K. Lu, Q. Li, X. Xi, T. Zhou and X. Zhao, Metal-Free Difluoromethylselenolation of Arylamines Under VisibleLight Photocatalysis, J. Org. Chem., 2020, 85, 1224; (b) K. Lu, X. Xi, T. Zhou, L. Lei, Q. Li and X. Zhao, Coppercatalysed direct difluoromethylselenolation of aryl boronic acids with Se-(difluoromethyl) 4-methylbenzenesulfonoselenoate, 
Tetrahedron Lett., 2021, 68, 152897; (c) H. Zhang, F. Yu, C. Li, P. Tian, Y. Zhou and Z.-Y. Cao, Iron-Catalyzed, Site-Selective Difluoromethylthiolation $\left(-\mathrm{SCF}_{2} \mathrm{H}\right)$ and Difluoromethylselenation $\left(-\mathrm{SeCF}_{2} \mathrm{H}\right)$ of Unactivated $\mathrm{C}\left(s p^{3}\right)-\mathrm{H}$ Bonds in $N$-Fluoroamides, Org. Lett., 2021, 23, 4721.

12 (a) S. Dix, M. Jakob and M. N. Hopkinson, Deoxytrifluoromethylthiolation and Selenylation of Alcohols by Using Benzothiazolium Reagents, Chem. - Eur. J., 2019, 25, 7635-7639; (b) A. Ariamajd, N. J. Gerwien, B. Schwabe, S. Dix and M. N. Hopkinson, Benzothiazolium salts as reagents for the deoxygenative perfluoroalkylthiolation of alcohols, Beilstein J. Org. Chem., 2021, 17, 83.

13 M. Tironi, L. M. Maas, A. Garg, S. Dix, J. P. Götze and M. N. Hopkinson, Deoxygenative Tri- and Difluoromethylthiolation of Carboxylic Acids with Benzothiazolium Reagents, Org. Lett., 2020, 22, 8925.

14 M. N. Hopkinson and S. Dix, Fluorine-containing compounds for use as nucleophilic reagents for transferring functional groups onto high value organic compounds, Eur. Pat. Appl EP19150201, 2019; M. N. Hopkinson and S. Dix, Fluorine-containing compounds for use as nucleophilic reagents for transferring functional groups onto high value organic compounds, International Pat. Appl. PCT/EP2020/050031, 2020.

15 K. Shibata and O. Mitsunobu, Preparation of 1,4-Dienes from 2-(2-Hydroxyalkylseleno)benzothiazoles by the Reaction Involving $\mathrm{Se} \rightarrow \mathrm{O}$ Azaaromatic Ring Rearrangement, Bull. Chem. Soc. Jpn., 1992, 65, 3163.

16 Selected examples of selenoesters in medicine: (a) N. DíazArgelich, I. Encío, D. Plano, A. P. Fernandes, J. A. Palop and C. Sanmartín, Novel Methylselenoesters as Antiproliferative Agents, Molecules, 2017, 22, 1288; (b) A. Csonka, A. Kincses, M. Nové, Z. Vadas, C. Sanmartín, E. Dominguez-Álvarez and G. Spengler, Selenoesters and Selenoanhydrides as
Novel Agents Against Resistant Breast Cancer, Anticancer Res., 2019, 39, 3777; (c) M. L. De la Cruz-Claure, A. A. Cèspedes-Llave, M. T. Ulloa, M. Benito-Lama, E. Domínguez-Álvarez and A. Bastida, InhibitionDisruption of Candida glabrata Biofilms: Symmetrical Selenoesters as Potential Anti-Biofilm Agents, Microorganisms, 2019, 7, 664; (d) T. Mosolygó, A. Kincses, A. Csonka, Á. S. Tönki, K. Witek, C. Sanmartín, M. A. Marć, J. Handzlik, K. Kieć-Kononowicz, E. Domínguez-Álvarez and G. Spengler, Selenocompounds as Novel Antibacterial Agents and Bacterial Efflux Pump Inhibitors, Molecules, 2019, 24, 1487; (e) G. Spengler, A. Kincses, T. Mosolygó, M. A. Marć, M. Nové, M. Gajdács, C. Sanmartín, H. E. McNeil, J. M. A. Blair and E. Domínguez-Álvarez, Antiviral, Antimicrobial and Antibiofilm Activity of Selenoesters and Selenoanhydrides, Molecules, 2019, 24, 4264. Selected examples of selenoesters as synthetic intermediates: $(f)$ A. P. Kozikowski and A. Ames, Copper(I) promoted acylation reactions. A transition metal mediated version of the Friedel-Crafts reaction, J. Am. Chem. Soc., 1980, 102, 860; $(g)$ D. L. Boger and R. J. Mathvink, Tandem free-radical alkene addition reactions of acyl radicals, J. Am. Chem. Soc., 1990, 112, 4003; (h) E. Wenkert and D. Chianelli, Nickel-catalysed decarbonylation of thioesters, J. Chem. Soc., Chem. Commun., 1991, 627; (i) S. Grélaud, V. Desvergnes and Y. Landais, Stereocontrolled $\left(\mathrm{Me}_{3} \mathrm{Si}\right)_{3} \mathrm{Si}$ H-Mediated Radical and Ionic Hydride Transfer in Synthesis of 2,3,5-Trisubstituted THF, Org. Lett., 2016, 18, 1542; $(j)$ G. Pandey, S. K. Tiwari, B. Singh, K. Vanka and S. Jain, $p$-Selective $\left(s p^{2}\right)-\mathrm{C}-\mathrm{H}$ functionalization for an acylation/alkylation reaction using organic photoredox catalysis, Chem. Commun., 2017, 53, 12337; (k) X. Fan and Z. Gu, Palladium/Norbornene-Catalyzed Ortho-Acylation and IpsoSelenation via $\mathrm{C}(\mathrm{O})-\mathrm{Se}$ Bond Cleavage: Synthesis of $\alpha$-Carbonyl Selane, Org. Lett., 2018, 20, 1187. 